\title{
Hormone Treatment Gives No Benefit Against Cognitive Changes Caused by Acute Sleep Deprivation in Postmenopausal Women
}

\author{
Maija Karakorpi ${ }^{1,2}$, Paula Alhola*,1,2, Anna Sofia Urrila ${ }^{3}$, Mervi Kylmälä4 ${ }^{4}$ Raija Portin ${ }^{5}$, Nea Kalleinen ${ }^{2}$ \\ and Päivi Polo-Kantola ${ }^{2,6}$ \\ 'Department of Psychology, University of Turku, Turku, Finland; '2Department of Physiology (Sleep Research Unit), University of Turku, Turku, \\ Finland; ${ }^{3}$ Department of Physiology, University of Helsinki, Helsinki, Finland; ${ }^{4}$ Department of Statistics, University of Turku, Turku, Finland; \\ ${ }^{5}$ Department of Neurology, Turku University Central Hospital, Turku, Finland; ${ }^{6}$ Department of Obstetrics and Gynecology, Turku University \\ Central Hospital, Turku, Finland
}

\begin{abstract}
The objective was to evaluate whether hormone therapy (HT) gives any benefit against the possible impairment of cognitive performance when challenged by acute sleep deprivation. Twenty postmenopausal women volunteered (age range 59-72 years, mean $=64.4$ years, SD =4.4): $10 \mathrm{HT}$ users and 10 nonusers. Eleven young women served as a control group for the cognitive age effect (age range 20-26 years, mean age 23.1 years, $\mathrm{SD}=1.6$ ). The subjects spent four consecutive nights at the sleep laboratory and were exposed to acute sleep deprivation of $40 \mathrm{~h}$. Measures of attention (reaction speed and vigilance), alertness, and mood were administered every $2 \mathrm{~h}$ during the daytime and every hour during the sleep deprivation night. Postmenopausal women performed slower than young controls, whereas young controls made more errors. In HT users, the recovery night did not fully restore the performance in the simple and two-choice reaction time tasks, but in nonusers it did so. Sleep deprivation had a detrimental, yet reversible effect on vigilance in all groups. In all groups, sleepiness started to increase after $15 \mathrm{~h}$ of sleep deprivation and remained elevated in the morning after the recovery night. Prolonged wakefulness or $\mathrm{HT}$ had no effect on mood. In conclusion, sleep deprivation impaired cognitive performance in postmenopausal as well as young women. Postmenopausal women kept up their performance at the expense of reaction speed and young women at the expense of accuracy. One night was not enough for HT users to recover from sleep deprivation. Thus, HT gave no benefit in maintaining the attention and alertness during sleep deprivation.

Neuropsychopharmacology (2006) 3 I, 2079-2088. doi:I0. I038/sj.npp. I 30 I056; published online I5 March 2006
\end{abstract}

Keywords: sleep deprivation; attention; hormone therapy; menopause; aging; woman

\section{INTRODUCTION}

Prolonged wakefulness causes not only sleepiness, but also changes in cognition, behavior, mood, and physiology (van den Berg et al, 2005; Drummond et al, 2000; Pilcher and Huffcutt, 1996). Subjective sleepiness increases as wakefulness continues, whether or not the lack of sleep causes a detectable decrease in cognitive performance (Casagrande et al, 1997). Sleep deprivation of $24 \mathrm{~h}$ is long enough to result in decreased performance on complex and long as well as simple and short cognitive tasks (Van Dongen et al, 2003; Smith et al, 2002; Thomas et al, 2000; Pilcher and Huffcutt, 1996). The longer the sleep deprivation, the shorter a test is sensitive in revealing performance impairment (Pilcher and Huffcutt, 1996).

\footnotetext{
*Correspondence: P Alhola, Department of Psychology, University of Turku, Fl-200। 4 Turku, Finland, E-mail: paula.alhola@utu.fi

Received I March 2005; revised 25 January 2006; accepted 27 January 2006

Online publication: 2 February 2006 at http://www.acnp.org/citations/ Npp020206050 I 4I/default.pdf
}

The effects of sleep deprivation on cognitive performance are task-specific as well. There are reports of negative effects on verbal learning (Drummond et al, 2000), visuomotor performance (Van Dongen et al, 2003), and working memory (Smith et al, 2002), yet the tasks that are the most vulnerable to preceding sleep loss are those requiring sustained attention and reaction speed (Van Dongen et al, 2003; Johnsen et al, 2002; De Gennaro et al, 2001; Harrison et al, 2000). Furthermore, as a result of sleep deprivation, performance tends to become more variable and error prone (Smith et al, 2002). However, in some studies reaction speed (Forest and Godbout, 2000) or accuracy (De Gennaro et al, 2001) have remained unimpaired.

The brain areas responsible for cognitive domains that are related to attention and memory include the basal forebrain, hippocampus, prefrontal cortex, and thalamus (Thomas et al, 2000; Portas et al, 1998; Posner et al, 1997; Pigott and Milner, 1993). The prefrontal cortex and thalamus are both proposed to be vulnerable to sleep loss as well, although the influence of sleep deprivation on cerebral activation is not yet clearly defined (Drummond et al, 2004; Drummond and Brown, 
2001; Harrison et al, 2000; Thomas et al, 2000; Portas et al, 1998). In addition, the basal forebrain and thalamus belong to the brain areas in which receptors for sex hormones, especially estrogen, are found (McEwen and Alves, 1999; Bixo et al, 1995). The mechanism of how estrogen is thought to exert its possible cognitive (Smith et al, 2001; Duff and Hampson, 2000; Duka et al, 2000; Rice et al, 2000) or moodenhancing (Miller et al, 2002) effects is through maintaining neural functions and decreasing their vulnerability to agerelated changes (McEwen and Alves, 1999). Despite this shared neural basis of memory, attention and alertness in some target brain areas for estrogen, the possible modulating effects of estrogen on reaction times and vigilance during sleep deprivation have so far not been considered. In a recent study, no modulating effect of estrogen on visual memory and shared attention during sleep deprivation was found (Alhola et al, 2005).

After menopause the estrogen deficiency in the endogenous hormonal milieu is permanent. Restoring the estrogen level by hormone therapy (HT) gives an opportunity to explore whether the debatable decline in cognitive abilities around the menopause is hormone dependent. Although the results of the effects of HT on cognition in postmenopausal women have not been unanimous (for a recent review see Sherwin, 2005), effects on attention and nonverbal memory (Smith et al, 2001; Resnick et al, 1998), visuomotor performance (Duka et al, 2000), and working memory (Duff and Hampson, 2000) as well as verbal memory and verbal fluency (Shaywitz et al, 2003; Rice et al, 2000; Resnick et al, 1998) have been reported. These and other previous studies on cognitive abilities of postmenopausal women have all been conducted in baseline conditions. So far, we know that in a mildly stressful condition HT modifies the physiological stress responses of postmenopausal women (Lindheim et al, 1992). HT may also increase resistance to sleep deprivation by improving sleep quality (Polo-Kantola et al, 1998).

A greater deterioration in cognitive performance induced by sleep deprivation in the aging has been suggested (Webb and Levy, 1982). So far, the effect of sleep deprivation on cognitive performance has mostly been studied in men (ie De Gennaro et al, 2001; Thomas et al, 2000) and therefore, also the effect of aging on cognitive performances during sleep deprivation is unclear in postmenopausal women. The objective of this cross-sectional study was to determine whether HT gives any benefit against the possible impairment of cognitive performance when challenged by acute sleep deprivation. We hypothesized that HT could help postmenopausal women to maintain their attention, alertness, and mood under such circumstances and facilitate recovery. To control for the possible cognitive age effects on these functions, a group of healthy young women was also included. We evaluated reaction speed, sustained attention, experienced sleepiness, and mood in healthy postmenopausal women on HT and in their controls in a study design with $40 \mathrm{~h}$ of wakefulness.

\section{MATERIALS AND METHODS}

\section{Subjects}

This study was conducted as a cooperative undertaking between The Sleep Research Units of the University of
Turku and Helsinki, Finland. Twenty postmenopausal women, aged between 59 and 72 years, were recruited through advertisements in Turku-area newspapers to a more extensive study 'Sleep in aging women', which evaluated the effects of aging and HT on quality of sleep and cognitive performance. The women who were current users of oral HT (estradiol hemihydrate $2 \mathrm{mg}$ + norethisterone acetate $1 \mathrm{mg})$ formed the group of HT users $(n=10$, mean age $=64.2$ years, $\mathrm{SD}=4.4)$, and those who were not on HT served as a group of postmenopausal controls (nonusers, $n=10$, mean age $=64.6$ years, $\mathrm{SD}=4.6$ ). Another control group consisted of young women, aged between 20 and 26 years (young, $n=11$, mean age $=23.1$ years, $S D=1.6$ ), all users of oral contraceptives (OC; ethinyl estradiol $20 \mu \mathrm{g}+$ desogestrel $0.15 \mu \mathrm{g})$. They were enrolled and examined at the University of Helsinki and were rewarded $300 €$ for participation. The postmenopausal women were unpaid volunteers. Serum follicle stimulating hormone $(\mathrm{FSH})$ and estradiol $\left(\mathrm{E}_{2}\right)$ levels were measured to estimate hormonal status. All young women were tested during the early phase of their menstrual cycle. It has previously been reported that OC use has no effect on reaction speed, sustained attention or alertness (Wright and Badia, 1999).

According to a physical examination, all the women were healthy. To exclude incipient hypo- or hyperthyroidism and anemia, normal values were expected in thyrotropin (S-TSH 0.4-4.5 mU/l) and blood hemoglobin (B-Hb 117-153 g/l). HT users and nonusers underwent electrocardiogram. Nonusers were required not to have used HT for at least 2 years before participation. The further exclusion criteria included a history of neurological, endocrinological, mental, and severe cardiovascular diseases, ongoing malignancies, inexplicable fits of unconsciousness, previously diagnosed and treated nocturnal breathing disorders and restless legs syndrome. Shift-workers and smokers were excluded. None of the participants used narcotics, prescribed psychotropic drugs or hypnotics, nor did they habitually consume alcohol or excessive amounts of coffee (more than five cups a day).

A regular sleep-wake rhythm (2200-2300 to 0600-0700 hours) was expected from all women before enrolling. To verify this, they kept sleep diaries for 3 weeks before and 1 week after their participation in the study. During this time, all hormone use not defined by the study protocol was prohibited. Those who were in the habit of consuming beverages containing caffeine, such as coffee, black tea, or coke, were requested not to have any for 1 week before the study and during their participation. The women were asked not to have any alcohol and to refrain from heavy physical activity and traveling abroad for 1 week before their participation.

The Beck Depression Inventory (BDI) was used to exclude subjects with depressive symptoms (Beck et al, 1961). A score of ten points was used as a cutoff point. The MiniMental State (MMS; Folstein et al, 1975) was given to the subjects at the beginning of the study to rule out incipient dementia. A score of 23 was used as a cutoff point. We observed no clinically significant depression or cognitive impairment among our subjects. Insomnia was measured with Basic Nordic Sleep Questionnaire (scale 5-25 points; Partinen and Gislason, 1995). Vasomotor symptoms, which are typical menopausal symptoms but possible at all 
ages, were assessed in all groups with two questions from modified Kupperman Index (night sweating and hot flushes, scale 2-8 points; Kupperman et al, 1953). The postmenopausal groups were comparable in age, education, MMS and BDI scores, as well as insomnia and menopausal symptoms. The characteristics of the study groups are summarized in Table 1.

Before participating in the study, the subjects visited the Sleep Research Unit for a personal interview of about $1-1.5 \mathrm{~h}$. During the interview, the exclusion criteria were ensured and the women were asked about their socioeconomic status, lifestyle, health history, and previous use of medications and hormones. In both postmenopausal groups, the mean duration of menopause was 15.0 years (HT users $\mathrm{SD}=6.2$, nonusers $\mathrm{SD}=5.4$ ). Seven of the 10 nonusers had previously used HT (Table 1) and the time since the cessation was 27-207 months (mean $=107$ months, $S D=64)$. The mean length of OC use in young controls was 41 months $(S D=29)$. The subjects were given study information, and they got to familiarize themselves with the Sleep Research Unit. All subjects signed an informed consent after receiving oral and written information. The study was approved by the Ethics Committees of the Turku University Central Hospital and the Helsinki University Central Hospital.

\section{Study Design}

The subjects spent four consecutive nights in the Sleep Research Unit. The laboratory conditions were carefully controlled and matched in the two laboratories. All measurements were carried out according to a strict timetable. Adaptation and baseline nights were followed by acute sleep deprivation of $40 \mathrm{~h}$. Sleep deprivation began at the conclusion of the baseline night, extending to the start of the recovery night. The night of recovery sleep lasted for $8 \mathrm{~h}$, from 2300 to 0700 hours (Table 2). Reaction speed, attention, and alertness were assessed every hour during sleep deprivation and, with few exceptions, every $2 \mathrm{~h}$ at other times. The excluded time points in all groups were
1000 hours after the baseline night and 2000 hours (and 2200 hours for Vigilance) before the recovery night. The reason for this exclusion was that the young women were participating in a magnetic resonance imaging study at the same time (Urrila et al, 2004). Tests were conducted before and after the adaptation and baseline nights, during sleep deprivation and finally, after the recovery night. The reaction speed tests together with the questionnaires were repeated 28 times, and the Vigilance test 12 times (Table 2). The first measurement was considered as baseline in each test and questionnaire.

The sleep laboratory rooms had no windows in either research unit, which ensured stable illumination. Temperature was recorded in both laboratories. During their leisure (nontesting) time, the subjects were allowed to carry out their own preferred activities such as reading, playing games, knitting, watching TV, or listening to the radio. They were also free to take a short walk outside. Sleeping and napping was prohibited. The subjects were always accompanied by laboratory staff who worked shifts.

\section{Methods}

The speed and accuracy of cognitive processing was examined with CogniSpeed software tests of reaction times (RTs) and vigilance (Revonsuo and Portin, 1995). The subjects were instructed to perform as quickly and accurately as possible, using the index finger of their preferred hand. At the first test session a practice round was taken before each task. Testing took place in a quiet room without windows. The staff members were not informed about the treatment group to which each subject belonged.

In the Simple reaction time (SRT) subjects had to press zero (0) on the keyboard as soon as the target number zero (0) appeared on the computer screen. Delay between appearances varied randomly between 1 and $4 \mathrm{~s}$, requiring quick preparation for reaction. In the two-choice reaction time (2-CRT), there were two target numbers: one (1) and two (2), and they appeared on the screen in a random order, with random delays as in the SRT. Subjects were to press the

Table I Background Characteristics at Baseline for the Three Study Groups, HT Users, Nonusers, and Young Controls on OC

\begin{tabular}{|c|c|c|c|c|c|}
\hline & $\begin{array}{c}\text { HT users } n=10 \\
\text { mean }(S D)\end{array}$ & $\begin{array}{c}\text { Nonusers } n=10 \\
\text { mean (SD) }\end{array}$ & $\begin{array}{l}\text { HT users vs } \\
\text { nonusers } P\end{array}$ & $\begin{array}{c}\text { Young } n=I \text { I mean } \\
\text { (SD) }\end{array}$ & $\begin{array}{c}\text { Young vs } \\
\text { postmenopausal } P\end{array}$ \\
\hline Age (years) & $64.2(4.4)$ & $64.6(4.6)$ & NS & $23.1(1.6)$ & $<\left.0.00\right|^{a, b}$ \\
\hline Cognitive impairment (MMS) & $28.0(1.8)$ & $26.8(2.3)$ & NS & $29.1(0.9)$ & $0.029^{\mathrm{b}}$ \\
\hline Depressive symptoms (BDI) & $3.5(3.2)$ & $6.4(3.8)$ & NS & $1.8(1.7)$ & $0.015^{b}$ \\
\hline Prior use of HT (months) & 149 (58) & $57(57)$ & 0.001 & - & - \\
\hline $\mathrm{FSH}(\mathrm{U} / \mathrm{l})$ & $6.0(6.6)$ & $77.1(19.4)$ & $<0.001$ & $3.8(2.8)$ & $<0.00 \mathrm{I}^{\mathrm{b}}$ \\
\hline$E_{2}(p m o l / l)$ & $208(108)$ & $27(5)$ & $<0.001$ & $95(84)$ & $0.002^{\mathrm{a}}$ \\
\hline
\end{tabular}

p-values indicate differences between the postmenopausal groups as well as between young women compared to HT users and nonusers.

${ }^{a}$ Difference was observed in young compared with HT users.

bDifference was observed in young compared with nonusers.

MMS = Mini-Mental State; BDI = Beck Depression Inventory; BNSQ = Basic Nordic Sleep Questionnaire; MKI= Modified Kupperman Index; HT=hormone therapy; $\mathrm{FSH}=$ follicle stimulating hormone; $\mathrm{E}_{2}=$ estradiol. 
Table 2 Timetable for the Study Indicates the Time Points at Which the Tests were Carried Out

\begin{tabular}{|c|c|c|c|c|c|}
\hline Time & Day I & Day 2 & Day 3 & Day 4 & Day 5 \\
\hline 7 & & Waketime; RT, S & Waketime; RT, S & Breakfast; RT, S & Waketime; RT, S \\
\hline 8 & & Breakfast & Breakfast, $\vee$ & V & Breakfast, V \\
\hline 10 & & & & $\mathrm{RT}, \mathrm{S}$ & $\mathrm{RT}, \mathrm{S}$ \\
\hline 12 & & (Day off) & Lunch; RT, S & Lunch; RT, S & Lunch \\
\hline 14 & & & $\mathrm{RT}, \mathrm{S}$ & $\mathrm{RT}, \mathrm{S}$ & \\
\hline 18 & To SRU at 1900 hours & To SRU at 1900 hours & Supper; RT, V, S & Supper; RT, V, S & \\
\hline 20 & $R T, S$ & $\mathrm{RT}, \mathrm{S}$ & $R T, V, S$ & & \\
\hline 22 & $R T, S$ & $\mathrm{RT}, \mathrm{S}$ & Snack; RT, V, S & Snack; RT, S & \\
\hline 23 & Bedtime & Bedtime & Sleep Deprivation & Bedtime & \\
\hline 24 & & & Snack; RT, V, S & & \\
\hline 5 & & & $\mathrm{RT}, \mathrm{S}$ & & \\
\hline 6 & & & $R T, V, S$ & & \\
\hline
\end{tabular}

Gray shading $=$ night asleep

$\mathrm{RT}=\mathrm{SRT}$ and 2-CRT; $\mathrm{V}=$ vigilance; $\mathrm{S}=\mathrm{VAS}$ and SSS; SRU = Sleep Research Unit.

Bold characters are significant in aiding the reader to perceive and comprehend the complex study protocol more readily.

corresponding key whenever a target appeared. In the SRT and 2-CRT, RTs of correct responses were measured in milliseconds (ms). In the 2-CRT, the number of errors was counted as well. In both SRT and 2-CRT, the final tests consisted of 40 trials.

The Vigilance test measured sustained attention. It was a visual test of letter cancellation, a monotonous task of $15 \mathrm{~min}$. The target letters mingled with nontargets occurred in the middle of the screen randomly, one at a time. The three target letters $(\mathrm{Y}, \mathrm{L}, \mathrm{M})$ appeared with a probability of $15 \%$. The presentation time for each letter was $300 \mathrm{~ms}$, and the interval between the letters varied between 500 and $3000 \mathrm{~ms}$. Subjects were instructed to press the space bar when a target letter appeared. In the statistical analysis of the Vigilance, the following dependent variables were considered: median RTs as a measure of speed, and the number of errors (false positives), and omission ratio (\%) as measures of accuracy.

In the Finnish version of the Stanford Sleepiness Scale (SSS; Hoddes et al, 1973), subjects were asked to assess their alertness at the moment on a scale from 1 ('feeling active and vital, alert, wide awake') to 7 ('almost in reverie, sleep onset soon, losing struggle to remain awake'). In visual analog scales (VAS) subjects were to assess how they felt at the moment with respect to the adjectives 'depressed', 'tired', and 'tense'.

\section{Statistical Methods}

The data were analyzed by repeated measures analysis of variance (ANOVA). When performance at baseline differed between the groups (RTs in 2-CRT and Vigilance and omission ratio in Vigilance), the baseline value was used as a covariate and analysis of covariance (ANCOVA) was carried out. The repeated measures model formula was $y_{i t k}=\alpha+\beta_{i}^{1}+\beta_{t}^{2}+\beta_{i}^{1} \beta_{t}^{2}+\beta^{3}+\varepsilon_{i t k}$. In this formula $y_{i t k}$ was the value of subject $k$ in group $i$ at time $t, \alpha$ was the overall mean, $\beta_{i}^{1}$ was the group $(i=1, \ldots, 3), \beta_{t}^{2}$ was the time $(t=1$, $\ldots, 28), \beta_{i}^{1} \beta_{t}^{2}$ was the interaction effect of group and time, $\beta^{3}$ was the value at baseline as covariate (included only when differences occurred in baseline performance) and $\varepsilon_{i t k}$ was the error term. The error term had a multinormal distribution $\mathrm{N}\left(\mathrm{O}, \mathrm{R}_{k}\right)$, where $R_{k}$ is a fitted covariance structure in the model. As the distributions of most parameters were skewed, square root, and logarithmic transformations were performed before statistical analyses. To allow for logarithmic transformations even when the original score was zero (0) (in which case logarithm is not defined), one (1) was added to each score.

There were 28 fixed time points for measurements of SRT, 2-CRT, SSS, and VAS and 12 for Vigilance. Both interaction and main effects of HT and sleep deprivation were studied. The interactions between HT and sleep deprivation effects were examined with multiple comparisons, in which observations from each time point were compared to baseline. Also, the group differences were analyzed. The results of these comparisons were Bonferroni corrected. When the interaction was not significant, the main effects of HT and sleep deprivation were tested. Tukey comparisons were performed for the main effects of group (HT effect) and Dunnet comparisons for the main effects of time (effect of sleep deprivation). Owing to low error and omission rates, observations from several time points were pooled together for the analysis. With this procedure, the accidental variability in these variables was eradicated (Table 3). $p$-Values of less than 0.05 were considered significant. 
Table 3 Measurement Times in 2-CRT Errors, Vigilance Errors, and Omissions were Pooled and Analyzed as Blocks

\begin{tabular}{|c|c|c|c|}
\hline \multicolumn{2}{|c|}{ Error blocks } & \multirow[b]{2}{*}{ Day } & \multirow[b]{2}{*}{ Time of the testing } \\
\hline 2-CRT & Vigilance & & \\
\hline । & & Day I & 2000 and 2200 hours \\
\hline$\|$ & & Day 2 & 0700 hours \\
\hline III & & & 2000 and 2200 hours \\
\hline \multirow[t]{2}{*}{ IV } & & Day 3 & 0700 hours \\
\hline & । & & 0830 hours \\
\hline V & & & 1200 hours and 1400 hours \\
\hline VI & & & 1600 hours \\
\hline VI & ॥ & & $1800,2000,2200$, and 2400 hours \\
\hline \multirow[t]{2}{*}{ VII } & & Day 4 & $\begin{array}{l}0100,0200,0300,0400,0500,0600 \text {, } \\
\text { and } 0700 \text { hours }\end{array}$ \\
\hline & III & & $0200,0400,0600$, and 0830 hours \\
\hline VIII & & & 1000,1200 noon and 1400 hours \\
\hline \multirow[t]{2}{*}{ IX } & & & 1600,1800 , and 2200 hours \\
\hline & IV & & 1600 and 1800 hours \\
\hline \multirow[t]{2}{*}{ X } & & Day 5 & 0700 and 1000 hours \\
\hline & $\vee$ & & 0830 hours \\
\hline
\end{tabular}

The analyses were performed with SAS statistical software package (SAS Institute, Cary, NC, release 8.2). Owing to missing observations in some time points, the MIXED procedure was used in the analyses. In the SRT, eight of the possible 868 observations (measurement times $\times$ number of subjects) were missing, in the 2-CRT $9 / 868$ and in the Vigilance $2 / 372$. In the SSS and VAS 'depressed' and 'tired' the corresponding numbers were $4 / 868$ in each, whereas in VAS 'tense' the numbers were $8 / 868$.

\section{RESULTS}

\section{Effects of Sleep Deprivation on Reaction Speed and Sustained Attention}

Simple reaction time. At baseline, performance in the SRT did not differ between the groups. In the course of the study, there was an interaction between group and time $\left(\mathrm{F}_{748}=2.41, p<0.001\right)$. In HT users and nonusers RTs became slower while in young controls on OC they remained at baseline level throughout the entire study (Table 4).

In HT users, RTs differed from baseline for the first time at 1200 hours before sleep deprivation (Day 3, $\mathrm{t}_{748}=-3.27$, $p=0.030)$. At 1400 hours RTs were back at baseline level and remained so for the next $11 \mathrm{~h}$, until 0100 hours. The nighttime decline began at 0100 hours, after $18 \mathrm{~h}$ of sleep deprivation $\left(\mathrm{t}_{748}=-3.49, p=0.014\right)$, and it was followed by a nocturnal trough from 0300 hours onwards $\left(t_{748}=-5.73\right.$, $p<0.003$ ). RTs remained impaired on the following day (Day 4 ) and they were at their slowest at 1800 and 2200 hours, which were the last measurements before retiring for the recovery night (after 35 and $39 \mathrm{~h}$ of preceding wakefulness). The baseline level of performance was not reached again even after the recovery night (from 0300 hours onwards $t_{748}$ values range -4.48 to -6.84 , all $p$-values $<0.003$ ).
In nonusers, RTs first differed from baseline and started their nocturnal trough at 2200 hours before the sleep deprivation night $\left(\mathrm{t}_{748}=-3.48, p=0.014\right)$, which was $3 \mathrm{~h}$ earlier than in HT users. The nighttime slowing of nonusers was continuous (all $t_{748}<-3.75, p<0.005$ ) with the peak of slowest RTs at 0700 hours, after $24 \mathrm{~h}$ of sleep deprivation (Day $4, \mathrm{t}_{748}=-6.91, p<0.003$ ). For the rest of Day 4 and until the recovery night, $\mathrm{RT}$ s remained elevated ( $\mathrm{t}_{748}$ values range -3.49 to -5.18 , all $p$-values $<0.005)$. After the recovery night (Day 5) RTs were at baseline level at 0700 hours, but they rose again at 1000 hours $\left(t_{748}=-3.26\right.$, $p=0.032$ ). In their reaction speed the postmenopausal women, especially HT users, were slower than young controls (Table 4).

Two-choice reaction time. At the baseline measurements of 2-CRT, the groups differed in their RTs $\left(\mathrm{F}_{2}=17.82\right.$, $p<0.001)$. In HT users and nonusers RTs were slower than in young controls ( $p$-values $<0.001)$. Like in the SRT, a group-by-time interaction in the 2 -CRT was observed in the course of the study $\left(\mathrm{F}_{722}=1.78, p<0.001\right)$. RTs increased only in HT users, whereas no change was seen either in nonusers or young controls (Table 4).

RTs of HT users rose during the night of sleep deprivation. The elevation of RTs first occurred at 0300 hours, after $20 \mathrm{~h}$ of continuous wakefulness $\left(\mathrm{t}_{722}=-3.60\right.$, $p=0.008$ ), and again at 0500,0600 , and 0700 hours, after $22-24 \mathrm{~h}$ of sleep deprivation $\left(\mathrm{t}_{722}=-3.16, p=0.046\right.$; $\mathrm{t}_{722}=-3.50, p=0.014$ and $\mathrm{t}_{722}=-3.89, p=0.003$, respectively). For the rest of the awakening hours, until the recovery night (Day 4), RTs stayed at baseline level. RTs were at their very slowest at 0700 hours after the recovery night (Day 5, $\mathrm{t}_{722}=-4.19, p<0.003$ ), but at 1000 hours RTs were back at baseline level. Again, the postmenopausal groups performed generally slower than young controls (Table 4).

The number of errors in 2-CRT was very low in all study groups. At baseline, the groups did not differ. During the study there was a main effect of group $\left(\mathrm{F}_{28}=3.71\right.$, $p=0.037)$ : HT users made fewer errors than young controls $\left(\mathrm{t}_{28}=2.71, p=0.030\right)$. No other group differences were found. There was also a main effect of time $\left(\mathrm{F}_{270}=6.04\right.$, $p<0.001)$. Already before the baseline night, from 2000 to 2200 hours onwards (Day 2), the number of errors grew smaller than at baseline on Day $1\left(t_{270}\right.$ values range -2.90 to -6.50 , all $p$-values $<0.05$, data not shown).

Vigilance. At baseline in the Vigilance, the groups differed in their RTs $\left(\mathrm{F}_{2}=11.21, p<0.001\right)$. RTs of HT users and nonusers were slower than those of young controls $(p<0.001$ and $p=0.023$, respectively). In the course of the study no group-by-time interaction or main effect of group was observed, but there was a main effect of time $\left(\mathrm{F}_{328}=7.07, p<0.001\right)$. During sleep deprivation RTs had slowed at 0200, 0400, 0600 and 0830 hours (after 19-25.5 h of continuous wakefulness, $\mathrm{t}_{328}$ values range $2.87-4.39$, all $p$-values $<0.05)$, as well as at 1800 hours $\left(\mathrm{t}_{328}=2.79\right.$, $p=0.046$ ). RTs were at their slowest at 0600 hours (Day 4 , after $23 \mathrm{~h}$ of continuous wakefulness, $\mathrm{t}_{328}=4.39, p<0.001$ ). At 0830 hours in the morning (Day 4), RTs were back at baseline level where they also remained until the end of the study (Figure 1). 
Table 4 Comparison of Simple Reaction Time (SRT, ms) and Two-Choice Reaction Time (2-CRT, ms) between the Three Study Groups, HT Users, Nonusers, and Young Controls on OC

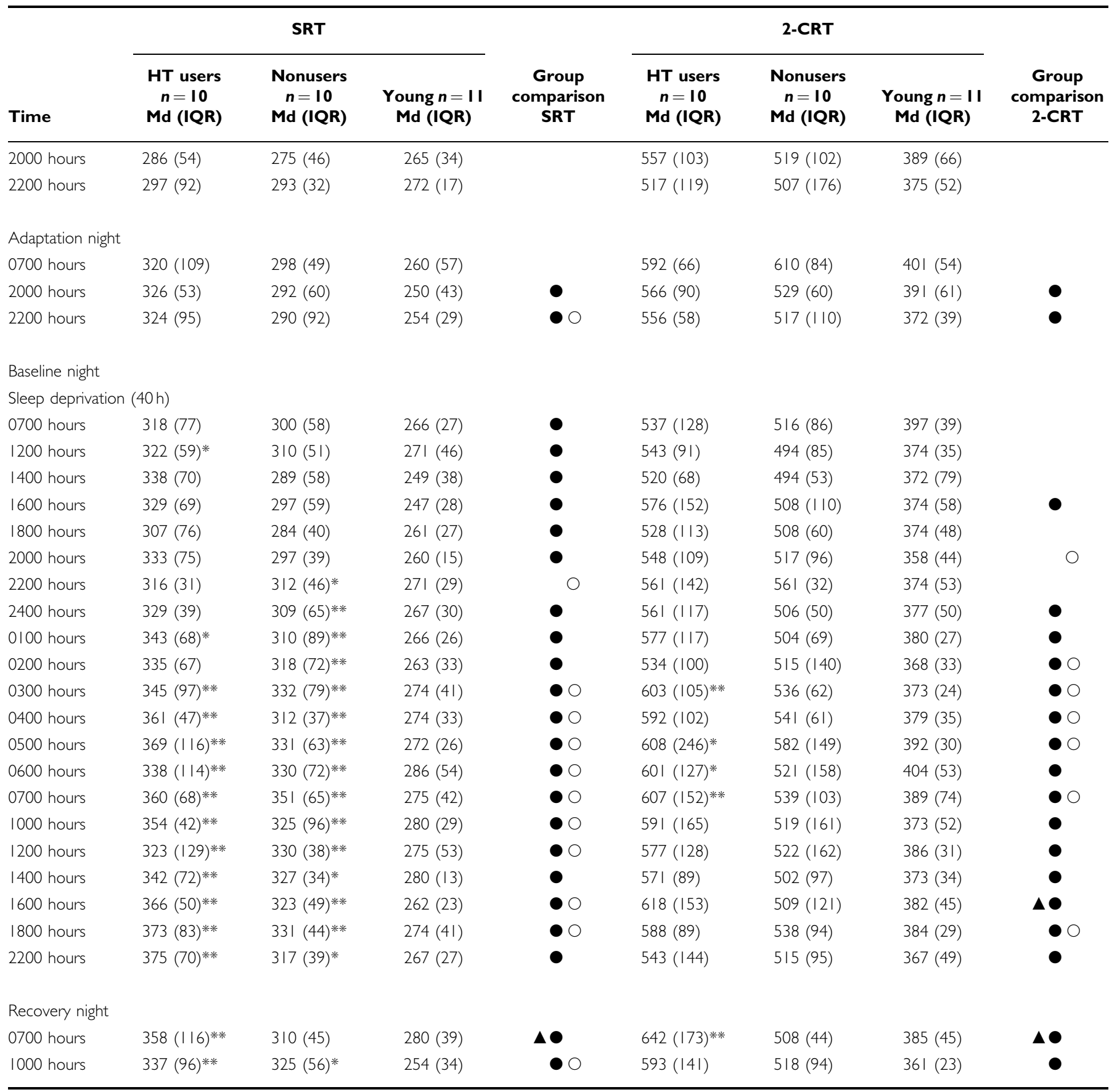

Interaction between group and time was observed. The longitudinal differences in reaction times compared to baseline in each group are marked with asterisks according to statistical significance. The differences between groups are plotted with triangles and dots (all significant $p$-values $<0.05$ ).

$* P<0.05 ; * * *<<0.0$.

$\mathrm{Md}=$ median; $\mathrm{IQR}=$ intertquartile range.

$\boldsymbol{\Delta}=\mathrm{HT}$ users vs nonusers; $\mathbf{O}=\mathrm{HT}$ users vs young; $\mathrm{O}=$ nonusers vs young.

The error rate in Vigilance was generally low and there were no differences between the three groups at baseline. An interaction between group and time was observed $\left(\mathrm{F}_{109}=2.58, p=0.013\right)$. In HT users, the number of errors stayed unchanged. In nonusers, the number of errors remained unchanged until following the recovery night when they made fewer errors than at baseline $\left(t_{109}=3.07\right.$, $p=0.011$ ). In young controls, the number of errors increased during the night of sleep deprivation, between 0200 and 0830 hours $\left(\mathrm{t}_{109}=-2.68, p=0.034\right)$, but thereafter there was no difference from baseline (Figure 2). During sleep deprivation, from 1800 hours to midnight (after 11$16 \mathrm{~h}$ of continuous wakefulness) HT users made fewer errors than nonusers and young controls $\left(t_{109}=2.69\right.$, 


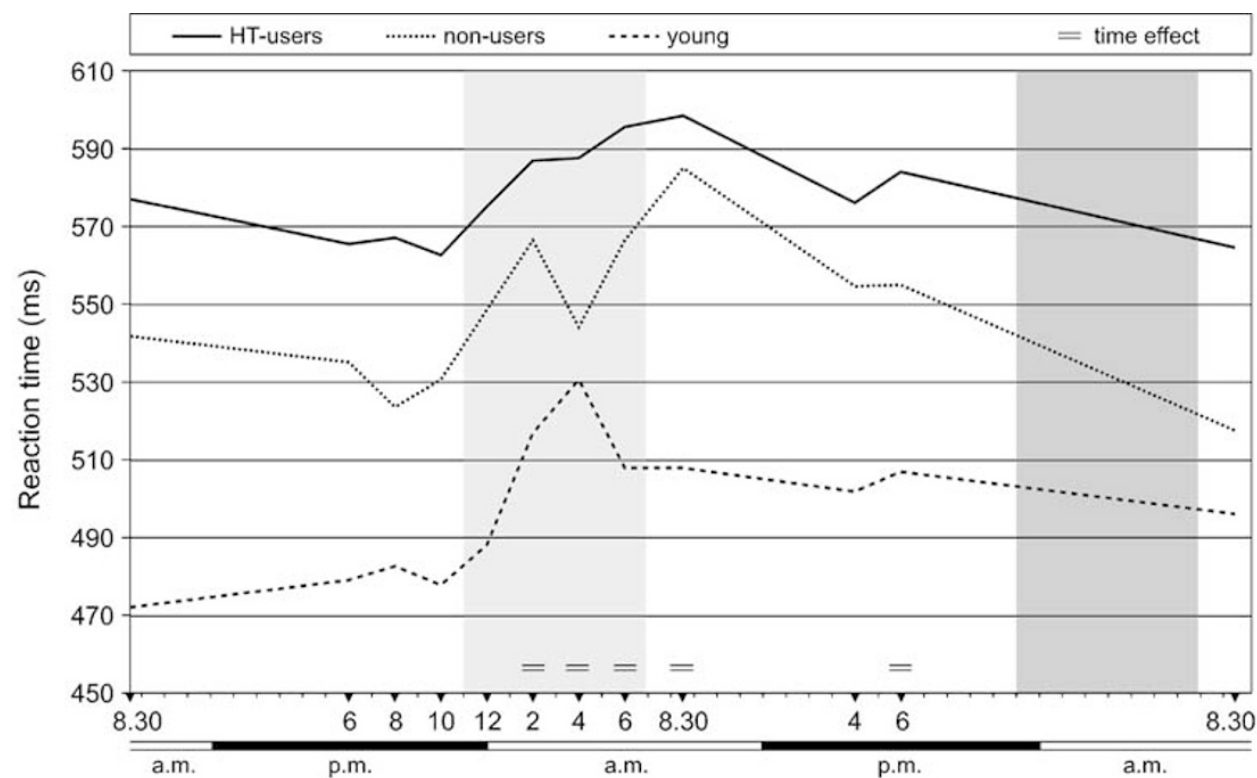

Figure I Reaction times in Vigilance for HT users, nonusers, and young controls on OC. Main effect of time was observed. The time points at which reaction times differed from baseline are plotted with double dash. Long tick marks on the $x$-axis indicate the times of testing. Dark gray shading $=$ night asleep, light gray shading $=$ night awake.

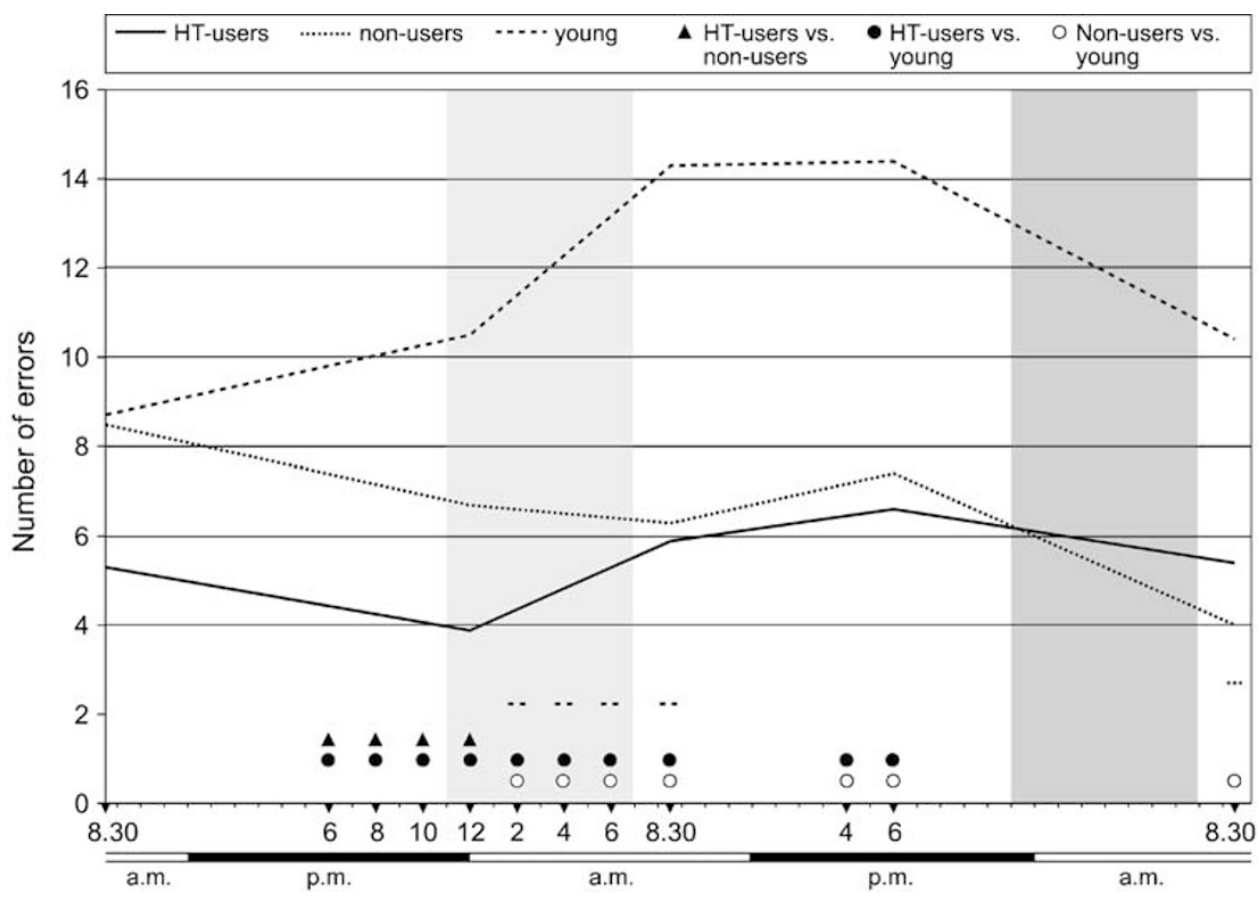

Figure 2 Errors in Vigilance for HTusers, nonusers, and young controls on OC. Interaction of group and time was observed. The differences in errors compared to baseline in each group are plotted with line corresponding to presented data. The differences between groups are plotted with dots and triangles. Long tick marks on the $x$-axis indicate the times of testing. Dark gray shading $=$ night asleep, light gray shading $=$ night awake.

$p=0.042$ and $\mathrm{t}_{109}=5.23, p<0.001$, respectively). From 0200 hours onwards during the rest of the sleep deprivation period both postmenopausal groups made fewer errors than young controls (all $\mathrm{t}_{109}$ values range $3.15-4.62, p<0.02$; Figure 2).

In the number of omissions groups differed at baseline $\left(\mathrm{F}_{28}=4.24, p=0.025\right)$. HT users had fewer omissions than nonusers $(p=0.021)$, but there was no difference between
HT users and young controls or nonusers and young controls. Later in the course of the study, there was neither a group-by-time interaction nor a main effect of group in the omission ratio. A main effect of time was found $\left(F_{120}=34.28, p<0.001\right)$. The omission ratio increased during sleep deprivation, staying above baseline level from 0200 to 1800 hours ( $t_{120}$ values range 5.16-6.88, $p$-values $<0.001)$. After the recovery night the ratio returned to 
baseline level. Omissions were generally few with the mean ratio of perceived targets ranging between 93 and $100 \%$ (data not shown).

\section{Effects of Sleep Deprivation on Sleepiness and Mood}

Stanford sleepiness scale. Self-rated sleepiness measured by the SSS fluctuated equivalently for all the groups in the course of the study. At baseline, the scores were similar in all groups and later, only a main effect of time was observed $\left(\mathrm{F}_{806}=23.45, p<0.001\right)$. In all groups, sleepiness was already increasing by 2200 hours before the adaptation night (Day $1, \mathrm{t}_{806}=4.06, p=0.001$ ) and still elevated at 0700 hours the next morning (Day 2, $\mathrm{t}_{806}=5.67, p<0.001$ ). This pattern reoccurred at 2200 hours (Day 2, $\mathrm{t}_{806}=3.10$, $p=0.036$ ) and 0700 hours (Day 3, $\mathrm{t}_{806}=4.71, p<0.001$ ) before and after the baseline night. On the third evening, starting again at 2200 hours (Day 3, after $15 \mathrm{~h}$ of sleep deprivation), sleepiness scores rose above baseline level, and stayed there until the first measurement after the recovery night (Day 5; $\mathrm{t}_{806}$ values range $4.23-10.32$, all $p$-values $<0.001)$. The very last measurement at 1000 hours returned to baseline level (data not shown).

Visual analog mood scales. Measured by VAS, the three groups did not differ in their moods at baseline. In depressive mood and feeling tense (data not shown), neither group-by-time interactions nor main effects of group or time were observed in the course of the study. In tiredness, the group-by-time interaction and the main effect of group were nonsignificant as well. However, a main effect of time was evidenced $\left(\mathrm{F}_{806}=14.28, p<0.001\right)$ with tiredness scores fluctuating in a similar manner as on the SSS scale. Tiredness was first elevated at 2200 hours before the adaptation night (Day $1, \mathrm{t}_{806}=3.58, p=0.008$ ) and it was still above baseline level at 0700 hours the next morning (Day 2, $\mathrm{t}_{806}=3.44, p=0.012$ ). At 2200 hours before the baseline night, subjects reported increased tiredness again (Day 2, $\mathrm{t}_{806}=3.50, p=0.010$ ). Unlike after the adaptation night, at 0700 hours after the baseline night (Day 3) no difference was seen, as compared to baseline. During daytime, subjects did not report increased tiredness. After $17 \mathrm{~h}$ of sleep deprivation, tiredness was elevated at midnight $\left(\mathrm{t}_{806}=3.24, p=0.023\right)$, and it remained so until 2200 hours (Day $4, \mathrm{t}_{806}$ values range 3.18-7.31, all $p$-values $<0.05$ ). After the recovery night (Day 5), tiredness diminished back to baseline level (data not shown).

\section{DISCUSSION}

Sleep-deprived postmenopausal women showed deterioration of reaction speed and attention. There was a minor difference between the performance of the HT users and nonusers to the disadvantage of the HT users. The HT users showed deterioration in all three cognitive tests and the nonusers showed deterioration in two tests. The reduced reaction speed of the HT users was restored by one night of recovery sleep in only one of the three tests. In the group of nonusers the recovery was more complete. The young controls on OC tended to make more errors than the postmenopausal women, especially more than the HT users, both at baseline and during sleep deprivation. In general, the postmenopausal women endeavored to maintain their performance at the expense of reduced reaction speed and the young women did so at the expense of accuracy. Subjective alertness was reduced equally in all groups as wakefulness continued, and it was not immediately restored by the recovery night. Mood was not affected by HT or sleep deprivation.

Whether HT has an effect on reaction speed or sustained attention during extended wakefulness has previously not been investigated in aging women. Some authors have reported that at baseline conditions HT improves working memory and related functions of directing, sustaining, and focusing attention and disregarding irrelevant stimuli (Smith et al, 2001; Duff and Hampson, 2000). The attentional domains are frontal lobe dependent (Posner et al, 1997; Stuss et al, 1995) and the frontal lobe, or the prefrontal cortex more specifically, is particularly vulnerable to sleep deprivation (Harrison et al, 2000; Thomas et al, 2000). Furthermore, the prefrontal cortex is one of the important target brain areas of estrogen (Duff and Hampson, 2000; McEwen and Alves, 1999). This shared neural basis makes it plausible that HT could ameliorate attentional performance during prolonged wakefulness. Contrary to our expectations, however, our results did not support this hypothesis. The performance of the HT users resembled that of the nonusers or was slightly worse. A possible explanation could be that the potential and previously obtained beneficial results of HT on nonsleepdeprived women are marginal and possibly clinically irrelevant. This idea received support from a recent large, randomized placebo-controlled trial (The Women's Health Initiative Memory Study; Rapp et al, 2003) in which HT did not improve cognitive function. However, conclusions drawn from these baseline studies may not be applicable to the present results on sleep-deprived healthy women.

In our study, the postmenopausal women, especially the HT users, were able to maintain their performance in terms of accuracy although this caused reduction of reaction speed. The performance of young controls, on the other hand, was rather stable in terms of reaction speed, but they kept up their level of performance at the expense of accuracy. This qualitative difference in the performance of the young and postmenopausal women indicates a speed/ accuracy tradeoff phenomenon, which reflects the choice of attentional focus (Rinkenauer et al, 2004). The difference in the choice of strategy between postmenopausal and young women may reflect a general age-related difference in controlled cognitive processing (Brebion, 2001). However, in some studies it has been reported that older adults performed slower and less accurately than young adults at baseline conditions (Lemaire et al, 2004). In our study at baseline, the performance was indeed slower in the postmenopausal than in the young women, but equally accurate in all groups. Consequently, the difference in strategies between older and young healthy women during the study course may be also due to different response to a demanding situation.

Smith et al (2002) have observed that despite mental effort, cognitive deficits start to increase within $1 \mathrm{~h}$ of the normal time of sleep onset. In our study groups, only subjective sleepiness was definitely on increase around the 
usual bedtime (between 2200 and 2400 hours midnight, that is, after $15-17 \mathrm{~h}$ of preceding wakefulness). This was somewhat before the objective measures of cognitive performance showed marked deterioration, which was between 2200 and 0400 hours (after 15-21 h of preceding wakefulness), depending on the group and test variable. A similar mismatch between subjective and objective measures has previously been reported by other studies (Leproult et al, 2003; Yang et al, 2004). For our subjects, the most demanding hours with respect to alertness were in the early morning. The same has been reported in previous studies as well (Babkoff et al, 1991; Mikulincer et al, 1989).

People tend to be sensitive to the negative effects of sleep deprivation, not only with respect to sleepiness, but with respect to mood as well (Pilcher and Huffcutt, 1996). However, the effect of sleep deprivation on mood is not unequivocal (Thomas et al, 2000). Although demanding, our study provoked no negative changes in mood in any of the study groups, which may reflect the high motivation of our subjects. At baseline conditions HT has been reported to alleviate tiredness and depressive mood (Polo-Kantola et al, 1998), but in our study the HT users did not differ from the other groups on scales measuring tiredness and mood.

The assessment of cognitive recovery after sleep deprivation showed that the postmenopausal women, especially HT users, were not resilient enough to restore their performance in all tests after one night of recovery sleep. Their reaction speed remained slower than at baseline level after the recovery sleep. The performance on the task measuring sustained attention was mostly recovered after the recovery night. Subjective sleepiness was still elevated at 0700 hours, immediately after awakening from the recovery sleep. This could be due to the circadian trough or to the fact that $8 \mathrm{~h}$ of recovery sleep was not enough to remove the need for sleep caused by acute sleep deprivation.

The CogniSpeed software, which was used in this study to measure reaction speed and sustained attention, has proved to be sensitive in revealing differences between groups of healthy subjects (Portin et al, 1999). The SRT and 2-CRT have satisfactory retest reliability and the Vigilance has even higher retest correlations (Portin, 2000). For subjective measures of alertness and mood we used the SSS and VAS. The SSS has widely been used in sleep deprivation studies, and it has been shown to be reliable in revealing fluctuations in alertness (see for instance Van Dongen et al, 2003; De Gennaro et al, 2001; Thomas et al, 2000; Portas et al, 1998). The VAS method is also widely used in different modifications (Leproult et al, 2003; De Gennaro et al, 2001). It is sensitive to predicted variations of subjective energetic activation and changes in emotions.

The results of our study may have been biased by subject selection through advertisements in newspapers, which may have favored women concerned about their cognitive abilities. However, by recruiting healthy women and carefully screening them before enrolment, the impact of diseases as confounding factors could be minimized. The small sample size may have limited the power of the study and so caused the lack of difference between the two postmenopausal groups, but on the other hand, the groups were homogeneous. Another source of bias rose from the cross-sectional design in which the use of HT was based on the women's own preference. A tendency for HT users to be healthier, more educated and to have higher socioeconomic status than age-matched nonusers has been shown in some studies (Duetz et al, 2000; Matthews et al, 1996), but in our study, the two postmenopausal groups did not differ in these respects. None of our subjects discontinued the study although their motivation may have been affected by financial compensation; the postmenopausal women were unpaid volunteers whereas the young women were financially rewarded for their participation.

We conclude that prolonged wakefulness impairs cognitive performance and alertness in postmenopausal as well as young women and that HT gives no benefit in keeping up the performance. Postmenopausal women maintain their performance at the expense of reaction speed and young women at the expense of accuracy. Prolonged wakefulness or HT has no effect on mood. A randomized study with a nondeprived control group will be needed to achieve a definite answer for how HT affects cognition and alertness during acute sleep deprivation.

\section{ACKNOWLEDGEMENTS}

This study was supported by European Commission Grant (QLK6-CT-2000-00499), Turku University Foundation and Finnish Cultural Foundation. We thank Tero Vahlberg, MSc, for statistical assistance.

\section{REFERENCES}

Alhola P, Tallus M, Kylmala M, Portin R, Polo-Kantola P (2005). Sleep deprivation, cognitive performance, and hormone therapy in postmenopausal women. Menopause 12: 149-155.

Babkoff H, Caspy T, Mikulincer M (1991). Subjective sleepiness ratings: the effects of sleep deprivation, circadian rhythmicity and cognitive performance. Sleep 14: 534-539.

Beck AT, Ward CH, Mendelson M, Mock J, Erbaugh J (1961). An inventory for measuring depression. Arch Gen Psychiatry 4: 561-571.

Bixo M, Backstrom T, Winblad B, Andersson A (1995). Estradiol and testosterone in specific regions of the human female brain in different endocrine states. J Steroid Biochem Mol Biol 55: 297-303.

Brebion G (2001). Language processing, slowing, and speed/ accuracy trade-off in the elderly. Exp Aging Res 27: 137-150.

Casagrande M, Violani C, Curcio G, Bertini M (1997). Assessing vigilance through a brief pencil and paper letter cancellation task (LCT): effects of one night of sleep deprivation and of the time of day. Ergonomics 40: 613-630.

De Gennaro L, Ferrara M, Curcio G, Bertini M (2001). Visual search performance across $40 \mathrm{~h}$ of continuous wakefulness: measures of speed and accuracy and relation with oculomotor performance. Physiol Behav 74: 197-204.

Drummond SP, Brown GG (2001). The effects of total sleep deprivation on cerebral responses to cognitive performance. Neuropsychopharmacology 25: S68-S73.

Drummond SP, Brown GG, Gillin JC, Stricker JL, Wong EC, Buxton RB (2000). Altered brain response to verbal learning following sleep deprivation. Nature 403: 655-657.

Drummond SP, Brown GG, Salamat JS, Gillin JC (2004). Increasing task difficulty facilitates the cerebral compensatory response to total sleep deprivation. Sleep 27: 445-451.

Duetz MS, Abel T, Meier C, Niemann S (2000). Self-rated health, life satisfaction and personal characteristics of postmenopausal women under estrogen replacement therapy. Maturitas 35: 71-79. 
Duff SJ, Hampson E (2000). A beneficial effect of estrogen on working memory in postmenopausal women taking hormone replacement therapy. Horm Behav 38: 262-276.

Duka T, Tasker R, McGowan JF (2000). The effects of 3-week estrogen hormone replacement on cognition in elderly healthy females. Psychopharmacology (Berlin) 149: 129-139.

Folstein MF, Folstein SE, McHugh PR (1975). 'Mini-mental state'. A practical method for grading the cognitive state of patients for the clinician. J Psychiatr Res 12: 189-198.

Forest G, Godbout R (2000). Effects of sleep deprivation on performance and EEG spectral analysis in young adults. Brain Cogn 43: 195-200.

Harrison Y, Horne JA, Rothwell A (2000). Prefrontal neuropsychological effects of sleep deprivation in young adults - a model for healthy aging? Sleep 23: 1067-1073.

Hoddes E, Zarcone V, Smythe H, Phillips R, Dement WC (1973). Quantification of sleepiness: a new approach. Psychophysiology 10: 431-436.

Johnsen BH, Laberg JC, Eid J, Hugdahl K (2002). Dichotic listening and sleep deprivation: vigilance effects. Scand J Psychol 43: 413-417.

Kupperman HS, Blatt MHG, Wiesbader H, Filler W (1953). Comparative clinical evaluation of estrogenic preparations by the menopausal and amenorrheal indices. J Clin Endocrinol 13: 688-703.

Lemaire P, Arnaud L, Lecacheur M (2004). Adults' age-related differences in adaptivity of strategy choices: evidence from computational estimation. Psychol Aging 19: 467-481.

Leproult R, Colecchia EF, Berardi AM, Stickgold R, Kosslyn SM, Van Cauter E (2003). Individual differences in subjective and objective alertness during sleep deprivation are stable and unrelated. Am J Physiol Regul Integr Comp Physiol 284: R280-R290.

Lindheim SR, Legro RS, Bernstein L, Stanczyk FZ, Vijod MA, Presser SC et al (1992). Behavioral stress responses in premenopausal and postmenopausal women and the effects of estrogen. Am J Obstet Gynecol 167: 1831-1836.

Matthews KA, Kuller LH, Wing RR, Meilahn EN, Plantinga P (1996). Prior to use of estrogen replacement therapy, are users healthier than nonusers? Am J Epidemiol 143: 971-978.

McEwen BS, Alves SE (1999). Estrogen actions in the central nervous system. Endocr Rev 20: 279-307.

Mikulincer M, Babkoff H, Caspy T, Sing H (1989). The effects of $72 \mathrm{~h}$ of sleep loss on psychological variables. $\mathrm{Br} J$ Psychol 80: 145-162.

Miller KJ, Conney JC, Rasgon NL, Fairbanks LA, Small GW (2002). Mood symptoms and cognitive performance in women estrogen users and nonusers and men. J Am Geriatr Soc 50: 1826-1830.

Partinen M, Gislason T (1995). Basic nordic sleep questionnaire (BNSQ): a quantitated measure of subjective sleep complaints. J Sleep Res 4: 150-155.

Pigott S, Milner B (1993). Memory for different aspects of complex visual scenes after unilateral temporal- or frontal-lobe resection. Neuropsychologia 31: 1-15.

Pilcher JJ, Huffcutt AI (1996). Effects of sleep deprivation on performance: a meta-analysis. Sleep 19: 318-326.

Polo-Kantola P, Erkkola R, Helenius H, Irjala K, Polo O (1998). When does estrogen replacement therapy improve sleep quality? Am J Obstet Gynecol 178: 1002-1009.

Portas CM, Rees G, Howseman AM, Josephs O, Turner R, Frith CD (1998). A specific role for the thalamus in mediating the interaction of attention and arousal in humans. J Neurosci 18: 8979-8989.

Portin R (2000). Cognitive Functioning in Midlife. Assessment by Mild Deterioration Battery and CogniSpeed ${ }^{\mathcal{C}}$. Dissertation, Annales Universitatis Turkuensis B240, University of Turku, Turku, Finland.
Portin R, Polo-Kantola P, Polo O, Koskinen T, Revonsuo A, Irjala $\mathrm{K}$ et al (1999). Serum estrogen level, attention, memory and other cognitive functions in middle-aged women. Climacteric 2: 115-123.

Posner MI, DiGirolamo GJ, Fernandez-Duque D (1997). Brain mechanisms of cognitive skills. Conscious Cogn 6: 267-290.

Rapp SR, Espeland MA, Shumaker SA, Henderson VW, Brunner $\mathrm{RL}$, Manson JE et al (2003). Effect of estrogen plus progestin on global cognitive function in postmenopausal women: the women's health initiative memory study: a randomized controlled trial. JAMA 289: 2663-2672.

Resnick SM, Maki PM, Golski S, Kraut MA, Zonderman AB (1998). Effects of estrogen replacement therapy on PET cerebral blood flow and neuropsychological performance. Horm Behav 34: 171-182.

Revonsuo A, Portin R (1995). CogniSpeed ${ }^{\odot}$ : The Computer Based Measurement of Cognitive Processing. University of Turku, Turku, Finland: AboaTech LTD.

Rice MM, Graves AB, McCurry SM, Gibbons LE, Bowen JD, McCormick WC et al (2000). Postmenopausal estrogen and estrogen-progestin use and 2-year rate of cognitive change in a cohort of older japanese american women: the kame project. Arch Intern Med 160: 1641-1649.

Rinkenauer G, Osman A, Ulrich R, Muller-Gethmann H, Mattes S (2004). On the locus of speed-accuracy trade-off in reaction time: inferences from the lateralized readiness potential. J Exp Psychol Gen 133: 261-282.

Shaywitz SE, Naftolin F, Zelterman D, Marchione KE, Holahan JM, Palter SF et al (2003). Better oral reading and short-term memory in midlife, postmenopausal women taking estrogen. Menopause 10: 420-426.

Sherwin BB (2005). Estrogen and memory in women: How can we reconcile the findings? Horm Behav 47: 371-375.

Smith ME, McEvoy LK, Gevins A (2002). The impact of moderate sleep loss on neurophysiologic signals during working-memory task performance. Sleep 25: 784-794.

Smith YR, Giordani B, Lajiness-O’Neill R, Zubieta JK (2001). Longterm estrogen replacement is associated with improved nonverbal memory and attentional measures in postmenopausal women. Fertil Steril 76: 1101-1107.

Stuss DT, Shallice T, Alexander MP, Picton TW (1995). A multidisciplinary approach to anterior attentional functions. Ann NY Acad Sci 769: 191-211.

Thomas M, Sing H, Belenky G, Holcomb H, Mayberg H, Dannals R et al (2000). Neural basis of alertness and cognitive performance impairments during sleepiness. I. effects of $24 \mathrm{~h}$ of sleep deprivation on waking human regional brain activity. $J$ Sleep Res 9: 335-352.

Urrila AS, Hakkarainen A, Heikkinen S, Vuori K, Stenberg D, Hakkinen AM et al (2004). Stimulus-induced brain lactate: effects of aging and prolonged wakefulness. J Sleep Res 13: 111-119.

Van den Berg J, Neely G, Nilsson L, Knutsson A, Landstrom U (2005). Electroencephalography and subjective ratings of sleep deprivation. Sleep Med 6: 231-240.

Van Dongen HP, Maislin G, Mullington JM, Dinges DF (2003). The cumulative cost of additional wakefulness: dose-response effects on neurobehavioral functions and sleep physiology from chronic sleep restriction and total sleep deprivation. Sleep 26: 117-126.

Webb WB, Levy CM (1982). Age, sleep deprivation, and performance. Psychophysiology 19: 272-276.

Wright Jr KP, Badia P (1999). Effects of menstrual cycle phase and oral contraceptives on alertness, cognitive performance, and circadian rhythms during sleep deprivation. Behav Brain Res 103: 185-194.

Yang CM, Lin FW, Spielman AJ (2004). A standard procedure enhances the correlation between subjective and objective measures of sleepiness. Sleep 27: 329-332. 